\title{
APUNTES DE ÉTICA DE LA LIBERACIÓN DESDE IGNACIO ELLACURÍA
}

\author{
José Joaquín Castellón Martín \\ Centro de Estudios Teológicos - Sevilla
}

\section{RESUMEN / ABSTRACT}

\begin{abstract}
Este artículo busca poner en diálogo la reflexión ética de Ignacio Ellacuría con la reflexión de filosofia ética y política actual, así como poner de manifiesto las virtualidades que su pensamiento crítico-realista posee. Comienza por un análisis personal del autor sobre el concepto de libertad que servirá de horizonte para situar las diversas reflexiones éticas y politicas, también la ética de la liberación ellacuriana.
\end{abstract}

This paper tryes to connect the ethic reflection from Ignacio Ellacuria with current philosophic ethic and politics, showing also the appropriate character of his critic and realistic thought nowadays. The paper starts with a personal analysis from the author about the concept of liberty that will help as a framework for placing diverse ethic and politic reflections, and also the liberation ethic from Ellacuria.

Este artículo tiene es un acercamiento a la ética de la liberación de Ignacio Ellacuría poniéndola en relación con las líneas de reflexión ética de la historia y, también, con las reflexiones ético-politicas de las últimas décadas del siglo XX. La filosofia de Zubiri, en la que Ellacuría encuentra su horizonte filosófico natural, no ha entrado en los debates filosóficos de Europa. Su precisión terminológica, su coherencia sistemática, su dificultad inherente lo han propiciado. Pero, a la vez, se ha creado entre los seguidores de Zubiri una especie de escolástica cerrada en sí misma que no ha asumido esa tarea tan importante para que un pensamiento tan profundo y de tanta amplitud de miras fecunde la reflexión filosófica del siglo XXI. Laín Entralgo y el propio Ellacuría lo hicieron, pero no todos sus 
seguidores han afrontado la tarea de hacer dialogar la filosofia del maestro con otros contextos históricos e intelectuales.

Ellacuría asume la tarea de situar la metafísica zubiriana en el contexto de la praxis histórica. Justo cuando estaba en la fase más creativa de su reflexión, ésta se vio truncada violentamente. La ética era una de las dimensiones más necesitadas de desarrollo de la propuesta zubiriana; Ellacuría la tenía como una de las prioridades de su proyecto intelectual, pero sólo podemos contar con acercamientos parciales o esquemáticos. Aun así en sus textos hay intuiciones suficientes para descubrir hacia dónde pretendia nuestro autor encauzar su reflexión.

La realidad de la explotación y la injusticia, del hambre y la guerra, del subdesarrollo y la violación de los derechos humanos eran el contexto en el que se desarrollaba su pensamiento. Esta característica es una virtualidad más del pensamiento ellacuriano para hacerlo dialogar con la reflexión ética y que pueda abrirnos caminos en la verdad.

Cuando se habla hoy de reflexión ética no se suele incluir en ese concepto la ética de la liberación. La actualidad de la reflexión ética se estructura hoy en tres grandes corrientes: el procedimentalismo rawlsiano, el comunitarismo en diversos autores norteamericanos y la ética del discurso en el ámbito europeo. También se reseña el viejo, y siempre reverdecido, relativismo emotivista que hace algunos años abanderó la llamada filosofía posmoderna.

En todas estas reflexiones éticas hay dos caracteristicas solidarias. La primera es el abandono explícito de la metafisica y de la reflexión sobre qué es la persona. Como consecuencia de esto, y en segundo lugar, la renuncia a plantear la dimensión personal de la moral, por decirlo en otras palabras, la alienación de la ética en ética política. Toda la reflexión moral se ha convertido en reflexión política. La dimensión personal de la moral se relega a una decisión privada e individualista. La corriente actual con más calado filosófico es la ética del discurso y postula un camino de pensamiento que recorre sendas de filosofia trascendental; pero el camino escogido es restringido: el análisis del hecho argumentativo, haciendo que enfoque su reflexión, de nuevo, en el ámbito político 
de la moral; sólo algunos de sus representantes, como la española Adela Cortina, hacen propuestas de valores y virtudes que avanzan en el ámbito de lo personal. Se apunta incluso a las virtudes cívicas que exige la democracia deliberativa. Pero los fundadores de esta corriente no entran habitualmente en el ámbito de lo personal.

Toda reflexión humana tiene una serie de supuestos cuya puesta de manifiesto y consideración es tarea de la filosofia. Uno de esos supuestos que muchas veces permanece inexplorados en estas éticas por su renuncia a abordar la metafisica de la persona, es el concepto de libertad. Todas las corrientes manejan ese concepto, toda ética ha de manejarlo; pero por esta suerte de "alergia" metafisica ninguna lo aborda en profundidad.

Un concepto primordial de toda reflexión ética es el concepto de libertad. Desde la realidad que las personas somos libres surge la necesidad de una reflexión ética. La liberta es la condición de posibilidad de que exista la dimensión moral de la persona. Después la ética podrá ser ética del bien, del deber o de la liberación; después el bien se definirá como felicidad, como ataraxia o como utilidad; después la liberación tendrá un componente libertario, liberal o liberador; después el deber podrá ser calvinista, kantiano o definirse desde la aceptación de una ley que se postula como incondicionada por su origen tradicional o divino. Pero el concepto de libertad sigue siendo, como decía, el supuesto de toda reflexión ética porque es la condición de posibilidad de la dimensión moral. Atendamos la realidad de la libertad humana.

\section{TRES DIMENSIONES DEL CONCEPTO DE LIBERTAD}

El concepto de libertad es el supuesto de toda teoría ética, y la configuración de la idea de la misma va a influir de manera radical en la propuesta de cada autor. Como ocurre siempre, es lo no problematizado, porque se considera como evidente, lo que está definiendo con más fuerza la marcha del pensamiento. Por eso, es muy pertinente que nos detengamos a ver cómo comprenden la libertad algunos autores de la ética contemporánea. Este acercamiento no tendrá pretensión ni de exhaustividad histórica ni sistemática. Es, simplemente, un comenzar a meditar. 
1.- Un concepto de libertad arranca de la contraposición de la realidad humana con la del resto de los animales. Ser libre sería no estar determinado por la ley del instinto, por la compulsión invencible de nuestras propias inclinaciones. Esta sería la perspectiva kantiana. Para Kant la verdadera libertad es la autonomía, en la que es la razón, no el instinto ni la tradición la que dicta la ley del comportamiento. Esta perspectiva, por su raíz kantiana, es también la de los autores que desde el liberalismo contractualista definen su reflexión sobre el deber y la justicia. Esta corriente de pensamiento define la libertad como no heteronomía. De tal manera que la libertad sería la razón dándose a sí misma una ley que seguir; esta ley que se da la razón a sí misma no puede ser otra por proceder de la razón que criterios de comportamiento de validez universal. La ley moral autónoma vendrá de la posibilidad de universalizar el propio comportamiento, así lo decía Kant.

Es quizás una configuración aparentemente simple de la libertad. Pero la genialidad de Kant la convirtió en una puerta al misterio de la dignidad personal. Kant saca un provecho inusitado a éste rasgo constitutivo de la libertad al conectarlo con la dignidad humana y con la realidad del hombre como un fin en sí mismo. Los textos sobre la dignidad humana de la Fundamentación de la Metafísica de las Costumbres son clásicos que nunca se deben olvidar.

El contexto histórico y filosófico de Kant explica que sea esta configuración tan básica de la libertad su punto de partida para esbozar el verdadero dinamismo de la moral. Kant, filósofo puritano y piadoso, tuvo que entendérselas con el emotivismo moral, por un lado, y el determinismo fisicalista, por otro y este contexto hizo que necesitara partir del concepto más simple de libertad como la no determinación heterónoma. Dejó a un lado toda la reflexión clásica, desde Platón a Santo Tomás, en la que se comprendía al hombre, desde su libertad, como el escultor de su propia personalidad.

Si la simplicidad de su punto de partida es justificable por su contexto histórico y filosófico, su brillantísimo y profundo desarrollo es fruto de su genialidad como filósofo. Es difícil de ponderar el proceso intelectivo que abre la no determinación de la acción a la auténtica autonomía moral. Su aportación, al partir de una configuración tan básica y elemental de la libertad ha sido poco 
discutible en unas épocas, en la que toda verdad se encontró al pairo de las criticas más disolventes. Toda persona es libre, toda persona tiene una dignidad irreductible; la persona es una realidad inconmensurable con ninguna cosa. La afirmación filosófica de la dignidad humana es uno de los aspectos más importantes del imponente legado kantiano.

Como en esta reflexión vamos a acercarnos al pensamiento ético de Ignacio Ellacuría, puede ser conveniente ver cómo su reflexión asume esta dimensión de la libertad. En terminología ellacuriana esta dimensión se nombra como "cargar con la realidad". El hombre no es conducido por sus formalizaciones instintivas, sino que puede "cargar con ellas" e ir donde le quiera; el hombre no tiene una indeterminación total, pero puede "cargar" con sus determinaciones biológicas y con toda la realidad en que se constituye para ser libre.

La concepción ellacuriana asume la libertad como no determinación, pero amplia su mirada. No comprende el marco de la libertad sólo desde la dimensión biológica, sino también social e histórica. Somos libres desde nuestra biología, y desde la cultura y la tradición en la que nos hemos constituido como personas. Esta indeterminación no puede compararse a unos grilletes abiertos que me permiten abandonar la prisión, sino como una bicicleta, que con el esfuerzo de las piernas y la sabiduría de la mirada, me permiten ir por el camino elegido. La bicicleta y mi propio cuerpo son pesos que mis músculos han de mover, pero son ellos -cuerpo y bicicleta-los que me permiten avanzar con rapidez. Biología, educación, cultura, tejido institucional, etc., todo ello nos permite ser libres, con todo ello ha de cargar el hombre en el camino de su libertad porque todo ello le posibilita ser libre: "El hombre se ve forzado a hacerse cargo de la realidad; ya no le basta con sentirse estimulado y responder a los estimulos, sino que ha de enfrentarse con las cosas como realidad. Esta es la función primaria de la inteligencia y no ejercerla debidamente es ya principio de ineticidad. El hombre se ve forzado a cargar con la realidad; la realidad, primariamente, la propia, pero también todo el resto de la realidad"1.

1 Ignacio Ellacuría, "Ética fundamental", en La lucha por la justicia. Selección de textos de Ignacio Ellacuría (1969-1989), Juan Antonio Senet (ed), Universidad de Deusto, Bilbao, p. 47. 
Esta comprensión de la libertad de actuación de la persona no entiende que nuestra libertad sea un mero margen entre nuestras pulsiones, como si pulsiones bio-psicológicas y libertad estuvieran enfrentadas. Para una filosofia realista de la libertad, las pulsiones son la fuerza que encauzada nos permiten vivir en libertad. La energía vital en el animal de realidades no es el límite de la libertad, sino su motor.

2.- Otra dimensión de la realidad compleja y profunda de la libertad es la realización del propio proyecto de vida. Vivir en libertad es vivir desde la realización un proyecto que nos dignifica y da un sentido a nuestra vida. La libertad se define desde el bien, desde el valor, desde la excelencia de la propia vida. Las personas somos libres por nuestra razón, no somos seres irracionales; esa libertad conlleva el reto de acoger en nuestra vida un sentido, un destino trascendente de nuestra existencia -no necesariamente en la acepción religiosa de la palabra-. Todas las personas somos libres, y esa libertad es un camino abierto que hemos de recorrer para desarrollar nuestra dignidad de personas.

Todas las personas somos libres, podrían decir los filósofos antiguos, pero la vida de muchas, de la mayoría, se va desarrollando sin relieve y sin color; recayendo, incluso, en las motivaciones más básicas de nuestra realidad corporal: la alimentación, la comodidad, el apareamiento. No somos animales, somos seres racionales; pero esa realidad nuestra es un reto a asumir, y para recorrer el camino en el que nos coloca nuestra libertad hemos de vivir con la fuerza que exige nuestra propia humanidad. Sin las virtudes de la justicia, la fortaleza, la templanza y la prudencia, nuestra vida poco se separa de la animalidad irracional, abandonada a la inmediatez de sus inclinaciones. Ser libre es vivir conforme al bien. Si pudiendo escoger el bien escogemos la burda satisfacción de nuestras inclinaciones, nuestra vida no puede llamarse digna de una persona libre. Platón, Aristóteles, Cicerón y todos los clásicos han desarrollado con gran belleza y profundidad esta intuición.

Ser libre es vivir conforme al bien; pero, ¿qué es vivir conforme al bien?, ¿qué es ese bien conforme al que tenemos que vivir?, ¿cómo definirlo? Esto no lo podía responder la ética sino la metafísica, porque preguntarse por el bien es preguntarse por el sentido último 
de la persona, y esto conlleva preguntarse por el fundamento de toda la realidad. Tanto la filosofia de Platón, como la de Aristóteles o la de Cicerón ratifican esto que decimos. Los autores clásicos coinciden en la relación entre la ética y la metafísica; aunque cada comprensión distinta de lo que es el "ser", tenga una comprensión distinta de lo que es el "bien"; para cada perspectiva metafísica hay una definición matizadamente distinta de "bien". Aun asi, son más las coincidencias que las divergencias, y todos estos autores postulan una moral que impulsa al hombre hacia lo mejor; todos ellos postulan una moral aristocrática -en el amplio sentido de la palabra-; una moral que propone ir configurando nuestra vida desde lo mejor. Para los clásicos la libertad verdadera es ir configurando nuestra persona desde el bien.

Esta ética clásica ha estado vigente durante más de veinte siglos en la cultura occidental. Y su pérdida de vigencia ha pasado una enorme factura, tanto a la sociedad como a las personas tomadas individualmente. Hemos dejado de tener argumentos para proponer a nuestros jóvenes un modelo de vida exigente, elevado, que busque "lo mejor". Enredados los intelectuales en filosofias del no-fundamento, han sido otras instancias las que les han propuesto de forma reiterativa y manipuladora, sus modelos de vida: el consumismo y el entretenimiento como caminos de felicidad. Es la moral propuesta a las masas, perdón, a los consumidores por el neocapitalismo. Más que ciudadanos o personas somos usuarios, consumidores, clientes...

Dramáticamente, son solo esos modelos los que hoy se proponen, porque no hay quien se atreva a hablar de esfuerzo moral, de sacrificio personal, de ideales éticos. El neocapitalismo propuso su elaboración filosófica ideologizadora en el llamado pensamiento débil o la filosofia posmoderna. Aunque esta afirmación habria que justificarla. Los filósofos del pensamiento débil acusaban de violencia metafísica a quien propusiera, con pretensión de universalidad racional, un horizonte moral de excelencia o de virtud.

A pesar de que pueda sorprender, el pensamiento de Ignacio Ellacuría sí que asume esta dimensión tan clásica de la ética y la moral. El concepto que Ellacuría arbitra para señalar esta dimensión de la realidad es el de "encargarse de la realidad". Nuestra libertad no sólo consiste en caminar libremente cargando con la realidad, sino 
que con nuestra libertad podemos encargarnos de la realidad en la que nos constituimos y, en cierta medida, transformarla, cambiarla. La libertad profunda es la de la persona que asume ese encargo de transformar la historia hacia lo mejor, hacia el bien y la justicia. "La realidad es la primaria responsabilidad del hombre, al hacerse cargo de ella debe encargarse de ella, ponerla sobre su propia existencia. El hombre se ve forzado a encargarse de la realidad. La realidad se le da al hombre como encargo; el gran encargo del hombre es su propia realidad con la que tiene que ser y la realidad de la historia. El esencial carácter práxico de la vida humana se presente éticamente como necesidad de encargarse de que la realidad sea como debe de ser, de que se haga con la realidad lo que se debe de hacer".

La filosofia de la praxis de Ellacuría reasume el clásico concepto de virtud, como configuración estable de la vida desde los hábitos y las costumbres, y lo resitúa en un contexto muy distinto. El hombre no sólo va a habituarse a vivir rectamente, se irá constituyendo realmente como justo; y no sólo será la propia persona lo que estaremos retados a ir configurando hacia el bien, sino que es toda la realidad social e histórica la que se nos muestra como susceptible de ser configurada desde la justicia, y nos reta a ir encargándonos de ella. El concepto clásico de virtud ha sido asumido por Ellacuria en el contexto de una filosofia de la realidad histórica. Para transformar la historia hacia una mayor humanidad se necesitan hombres y mujeres de esperanza, dueños de sí mismos y entregados a ir realizando ese proyecto utópico.

3.- El tercer concepto de libertad está enraizado en el pensamiento profético judío y ha ido recorriendo la historia de la humanidad, en gran medida a través del cristianismo. Los Profetas, los Padres de la Iglesia, San Agustín y Santo Tomás, Francisco de Victoria y Bartolomé de Las Casas, Martin Buber y Enmanuel Levinas, son algunos de sus representantes. Aunque, como es evidente, con diferencias importantes entre ellos.

En esta tercera configuración de la libertad, ser libre no es meramente no estar condicionado, ni siquiera ir esculpiendo de la

2 Idem. 
mejor manera la figura de nuestro yo. No es que lo excluya, pero se entiende que la libertad no se funda en algo que la persona posee, sino en la interpelación que el otro nos hace y en la que nos regala nuestra propia libertad.

Ser libre es vivir abierto al otro en la propia realidad. Sin la interpelación del otro no dejaríamos de ser un sistema previsible de comportamiento, un sistema cerrado de realidad; sin la apertura al otro, todo lo que vivimos o hacemos no deja de ser evidente o larvado egoísmo. El otro puede ser el hermano, aquel a quien quiero; el otro puede ser el pobre que necesita de mí; el Otro puede ser Dios mismo ante quien me siento querido y ante quien descubro mi nimiedad y mi pobreza. Ser libre, en esta tercera dimensión de la libertad, es dejarse poseer por el otro, entregarle la propia libertad; ser libres viene a ser dejar que el otro tenga tal poder sobre nosotros mismos que nos permita ir más allá de lo que hasta ahora somos. Ser libre es vivir "extasiado" en lo otro, en los otros, en el Otro. No se vive la verdadera libertad hasta que Alguien se apodera de nuestra realidad.

La verdadera libertad del artista, del pintor, no está en pintar lo que quiera, ni siquiera en ir perfeccionando su técnica pictórica. La verdadera libertad del pintor está en encontrarse poseído por una experiencia estética que lo desborda y que se ve retado a expresar con formas y colores, con texturas y contrastes, siendo consciente siempre que lo que realice no hará justicia a lo que se ha adueñado de su propio pincel.

Ser libre no es simplemente ser auténticamente lo que soy. Ser libre es ser-en-el-otro recorriendo un camino cuya principal virtud no es mi propia realización, sino el encuentro y la comunión. Todo lo demás acaba por ser una egoísta auto-realización, que es, muchas veces, una formas de buscarnos a nosotros mismos con desesperación.

Este concepto de libertad, en la que la persona funda su propio ser en el otro, se ha dado en pensadores de tradición cristiana que asumian la manera clásica de afrontar la ética. De tal manera que su propuesta moral se entretejía con su profunda experiencia religiosa. Ha sido ya en el siglo XX cuando esta forma de encarar la libertad se ha expresado, por pensadores de tradición judía, desde la propia filosofia. La negación del otro que se dio en el nazismo, como medio de afirmar 
la libertad y excelencia de la propia raza, impulsó la comprensión de que el otro no es el limite de nuestra libertad, sino el camino necesario para vivirla. El olvido del otro, la afirmación solipsista de nuestra existencia nos lleva al vacío y al absurdo existencial, como le ocurriria a Sartre. Esta tercera dimensión de la libertad necesita una concepción metafísica de la realidad que supere el sustancialismo $\mathrm{y}$ que plantee un orden trascendental, no cerrado, no definido, no acabado, sino estructuralmente dinámico y esencialmente abierto. Porque lo que somos en realidad no está acabado ni definido, porque lo que la verdad de nuestra realidad personal no está en lo que soy sino en el salir de mi propio mundo, de mi propio ser.

Dicho de otra manera: la verdadera libertad no es tener poder sobre lo real y encargarnos de transformarlo. La verdadera libertad consiste en que lo real en la plenitud de su dinamismo y realidad, que es la intimidad del otro, tiene poder para transformarnos. En muchos momentos señala Ignacio Ellacuria ese poder, pero lo hace en un contexto teológico, haciendo ver que es Dios mismo quien a través de las víctimas, de los que sufren, de los pobres, Quien se apodera de nuestra realidad recreándonos. Pero hay un esquema titulado "Ética fundamental" que asume esta dimensión del poder de lo real desde una perspectiva personal e interpersonal: "Este hecho del influjo sobre los demás hace que el hombre deba tener en cuenta a los otros, porque su acción no queda fuera de si mismo, sino que configura a los demás. (...) La realidad personal tiene una existencia estrictamente personal y comunitaria, sólo en la cual cobra su auténtica condición de persona. (...) Hay una referencia a la otra persona en tanto otra persona, en tanto que otro como yo, y en esa referencia es donde el hombre queda plenariamente personalizado y plenariamente desarrollado"s.

La ética de Ignacio Ellacuría es un proyecto meramente esbozado. Sus intuiciones y reflexiones se vieron truncadas en un momento de madurez creativa, cuando la comprensión de la realidad moral estaba ya perfilada para expresarla con la profundidad y exactitud que manifestaba en todos sus escritos.

3 Ibid, 48. 
Las tres configuraciones del concepto de libertad son verdaderas, ya que son complementarias. Cada una de ellas se funda en una dimensión real de la persona. Una reflexión ética a la altura de los tiempos ha de asumir estas tres dimensiones de la realidad humana.

\section{TRES CONCEPTOS DE JUSTICIA}

En los inicios de la reflexión sobre la moral, la dimensión personal y la dimensión social han estado intimamente relacionadas. Las éticas clásicas se definían desde la idea de bien. Esta idea proyectada en la persona daba a luz lo que había de ser persona virtuosa, proyectada sobre la sociedad daba a luz cómo tenía que ser una sociedad justa. Desde la orientación de nuestra reflexión, centrada en la realidad del acto libre, podemos apuntar que los tres conceptos de libertad, enraizados en tres momentos de la misma, dan también tres conceptos diversos de justicia.

Nos vamos a centrar en el último tercio del siglo XX. En 1971 aparece un libro largamente esperado: la Teoría de la justicia de John Rawls. En 1976 se publica la Teoría de la acción comunicativa de Jürgen Habermas. De esa década son también las publicaciones de H.O. Apel sobre ética discursiva. Los intentos de la década de los 70 estarán dominados por la preocupación de fundamentar la Ética en una perspectiva universalista y por lo mismo, deontológica. La década siguiente va a estar marcada por una matriz diferente. En 1981, aparece Tras la virtud de Alasdair MacIntyre que va a ser, sin ningún género de dudas, el libro de Ética más comentado y discutido internacionalmente en los años 80.

La comprensión kantiana de libertad y de dignidad de la persona ha dado un fruto realmente interesante: la "Teoria de la Justicia" de J. Rawls. Este profesor norteamericano ha centrado su reflexión de ética social sobre la exigencia de ofrecer a todas las personas un ámbito en el que todas puedan desarrollar sus capacidades y virtualidades, de la manera más adecuada posible, desde su propia decisión. Todos hemos de vivir la libertad en la auto-determinación de la propia vida; y, en este aspecto, una sociedad justa es la que busca una fundamental igualdad de todos para poder desarrollar su propia vida; y en la que todos tiene que tener la libertad de vivir 
lo que le parece bueno o racional; todos han de poder desarrollar humanamente sus virtualidades personales sin que ninguna carencia o límite heterónomo se lo impida. Por eso, nos dirá Rawls, en las sociedades justas lo razonable ha de tener siempre primacía sobre lo racional, el marco de libertad común sobre las opciones lícitas pero personales, lo justo sobre lo bueno. Entiéndase que razonables son aquellos bienes o valores que se han de considerar común a cualquier persona, independientemente de todo elemento de mentalidad cultural, posición social o creencias políticas o religiosas. La sociedad justa, en el horizonte fundamental de la libertad, ha de regirse por el criterio del "maximin", es decir, procurar que los mínimos vitales de todos sus miembros sea el máximo posible para que la libertad de todos sea una realidad y no una mera formalidad. Las únicas desigualdades admitidas serian las que potenciaran un beneficio social subsiguiente.

La propuesta de Rawls busca conseguir unas cotas importantes de solidaridad y de justicia social, partiendo, como parte, de la afirmación irrestricta de la libertad individual que da a luz la sociedad a través de una especie de "contrato social", pero realizado bajo el "velo de la ignorancia", bajo el cual las personas sólo son personas, sin considerar la materialidad de su propia personalidad. Hasta aquí un esbozo sintético, esquemático, que no pretende sino recordar algunos elementos estructurales.

El contractualismo de Rawls es muy interesante, pero adolece de carencias filosóficas reseñables. Quizás la más evidente es que no es explica en virtud de qué principio o criterio una persona ha de dejar de velar por sus intereses particulares, a través del recurso del velo de la ignorancia, para beneficiar a todos los miembros de esa sociedad por igual. Esa opción ética por la igualdad, por la dignidad de la persona y por la justicia social da por supuesto la mayor parte de los problemas de la experiencia moral personal.

Este dinamismo de universalidad parte de las decisiones de los individuos de una sociedad. Pero la realidad no está siempre a disposición de las decisiones de los individuos. Consciente de esto, Ellacuría asume la universalidad de Kant desde una perspectiva post-epistemológica y post-decisionista. "Sólo puede ser aceptable para la humanidad nueva un proyecto global que sea 
universalizable ${ }^{\text {"4 }}$. Si un proyecto civilizatorio no es factible de ser realizado por todos los pueblos, será en su raíz injusto, aunque sea decidido por la mayoría de ciudadanos de un país poderoso, que siguen siendo una pequeña minoria de la humanidad. La justicia que conlleva la universalización de las opciones éticas puede ponerse en relación con el primero de la liberación de toda situación de pobreza alienante, con lo que se consigue una verdadera universalización histórica. "La universalización ha de hacerse desde la opción preferencial por los pobres, pues, la hasta ahora hecha desde la opción preferencial por los ricos y poderosos ha traido a la humanidad más males que vienes"s. No hay universalización verdadera si no se asume, desde la realidad, la opción preferencial por los pobres. Esto, en sentido estricto, no está en oposición a lo que propone Ralws, pero la propuesta de Ellacuría matiza de manera significativa el contractualismo ralwsiano.

Otro aspecto a valorar es el papel de la dimensión personal de la moral; al centrarse exclusivamente en la teoría de la justicia, Rawls deja ensombrecida la dimensión personal de la moral, para la que no propone criterios morales. Esa dimensión entra dentro de lo razonable y, por tanto, queda en el ámbito privado. Esta separación de la justicia en su dimensión social de las motivaciones morales personales deja sin asiento ni fundamento su propuesta. Él conscientemente no lo busca, lo supone, pero si ese velo de la ignorancia se "echa" en las cosmovisiones comunitarias que impulsan la inquietud por la justicia estariamos en una situación contradictoria.

A algunas de estas carencias intenta responder la otra corriente que hoy por hoy compite por el ámbito académico norteamericano: el comunitarismo. Para los comunitaristas, como Taylor, McIntyre o Sandel, cada uno a su manera, la libertad verdadera no significa prioritariamente actuación incondicionada sino, como para los clásicos, actuación que nos lleve a la perfección de la propia vida en la sociedad en la que vivimos. Su apelación última es a la ética aristotélica, o hegeliana en el caso de Taylor, que proponía un ideal de vida materialmente configurado, unas virtudes realmente

4 I. Ellacuría, "Utopía y profetismo", en Mysterium Liberationis. Conceptos fundamentales de la teología de la liberación, Trotta, Madrid, 1990, p. 409.

5 Ibid p. 410. 
rectoras de la vida del noble griego, una finalidad de la persona que se centraba en la excelencia tal y como su cultura lo entendia. Los autores comunitaristas echan en falta, no sin razón, en la reflexión ética de la modernidad un ideal material de bien que sea rector y guía de los comportamientos de las personas; y ven en esa carencia la causa de muchos problemas de nuestras sociedades.

Tras la virtud se configura como reflexión que se elabora desde la teoría y la narración histórica. Se nos narra una historia intelectual y moral: la decadencia de la moralidad en la edad moderna y las posibilidades que quedan para un posible resurgir de ella. Frente a la vaciedad formalista de una filosofia moral que quería reducirse al estudio del lenguaje moral, y frente a un pacto social llevado a cabo bajo el velo de ignorancia y la neutralización de las diferencias sociales, históricas y culturales, MacIntyre nos presenta una ética inmersa en la historia real, nos habla narrativamente de historias reales de la moralidad e inmoralidad reinantes en nuestra cultura.

Esta obra narra el nacimiento, crecimiento, decadencia y desaparición de la tradición de las virtudes. El libro comienza con una hipótesis catastrofista del presente ético: vivimos una situación cultural en la que la moralidad, y la misma teoría ética, no son más que simulacros de lo que fueron, elementos residuales yuxtapuestos y desordenados del esquema conceptual que aportaba la tradición de las virtudes. Desaparecida la virtud, tras ella, sólo quedan simulacros de moralidad, fragmentos de un esquema conceptual sin los contextos que le daban significado ${ }^{6}$. Desde este análisis en negativo busca un nuevo concepto de virtud, pero por su desconfianza de la metafisica no lo buscan desde el análisis de la realidad personal o de la acción humana, tal y como lo hizo Aristóteles; sino que lo encuentran en los ideales que, como comunidad instituida, están en el acervo tradicional y se ve necesario potenciar.

Esta opción tiene un riesgo evidente de nacionalismo cultural etnocéntrico. Por ejemplo, en un famoso libro de Michael J. Sandel ${ }^{7}$, en el que se plantean todo tipo de problemas morales de la sociedad

I. MacIntyre, Tras la virtud, Ed. Crítica, Barcelona, 1987, p.15.

7 Michael J. Sandel: Justicia. ¿Hacemos lo que debemos?, Debolsillo, Barcelona, 2013. 
norteamericana, la inmigración y las deportaciones de inmigrantes a países donde su vida va a peligrar por violencia o pobreza no es ni siquiera mencionada; tampoco considera un problema de justicia para la sociedad americana la presencia del ejército norteamericano en países del tercer mundo, la venta de armas de empresas norteamericanas a dictaduras militares, o la actividad de las multinacionales que provocan un claro colonialismo cultural, y otras acciones bastante cuestionables desde parámetros de justicia social.

En la perspectiva de Ellacuría el dinamismo de la tradición asume esta dimensión aportada por el comunitarismo: nuestras tradiciones nos aportan una forma de estar en la realidad imprescindible para nuestra vida humana. Pero el dinamismo de la tradición no es meramente receptivo, sino que ha de entenderse en un movimiento de constante actualización a las circunstancias cambiantes de la sociedad y la cultura. Esta transformación de las ideas y valores que nos han hecho ser personas no puede ser sólo noética o de hermenéutica idealista, el dinamismo de la tradición, el auténtico "tradicionar" los conceptos de "justicia", "bien común" o "virtud humana", ha de hacerse teniendo en cuenta toda la realidad socio-económica en la que vivimos. Comprendiendo la historia como realidad histórica, la hermenéutica ha de ampliar su horizonte estructural y no dirigirse sólo al pasado intelectual, sino al presente, que nos va constituyendo, $\mathrm{y}$ al futuro, que queremos construir más humano. "Historia no es primariamente autenticidad critica sino proceso de realización $y$, en definitiva, proceso de liberación. Cuando se habla de vuelta a la historia, puede entenderse la vuelta como recurso a los datos históricos $y$ entonces estamos ante un proceso meramente metodológico, por muy necesario que se lo considere -y asi debe considerárselo- para no perderse en fantasías o en especulaciones; pero puede entenderse como una vuelta a lo que es la totalidad estructural de lo real en su proceso unitario como lugar primario de veri-ficación"s. Este volver a la historia, como Husser apelaba a volver a las cosas mismas, nos desvelará si los conceptos valorativos que vivimos están impulsando una mayor humanización, o, por el contrario, pareciendo defender el bien común o la justicia, salvaguardan, en realidad, privilegios injustificables.

8 I. Ellacuría, "Hacia una fundamentación del método teológico latinoamericano", en Revista de Estudios Centroamericanos 322-323 (1975), p. 415. 
Hay un tercer concepto de Justicia que asume la tercera dimensión de la libertad que habíamos señalado: el otro como camino de nuestra propia realización. Pero en el ámbito del primer mundo se ha desarrollado de manera parcial. La ética del discurso asume, en parte, esta dimensión. Para la ética del discurso, el camino de definición de lo que sea justo pasa por el diálogo argumentativo. En ese sentido está presente el otro como camino de la propia realización. Esta corriente de ética se reconoce fundamentalmente kantiana, bien que su análisis trascendental no se hace desde la libertad del individuo que afronta su propia vida, sino desde la interrelación social que supone el diálogo argumentativo moral. El sujeto ético, para Apel y Habermas, es el sujeto que para vivir en sociedad busca ponerse de acuerdo con los otros sujetos con los que ha de convivir. La forma que tiene de hacerlo es a través del discurso racional. La ética del discurso asume la interrelación personal como camino ineludible de crecimiento de la justicia y el bien común. Pero su comprensión del otro es significativamente reductiva. El otro es el otro en tanto argumentador, en tanto persona que razona y expone argumentos racionales de sus posturas ético-politicas. El sujeto mismo es definido de forma restrictiva, limitada. No se asume al otro en un camino de comunión que enriquece mi propia realidad y que me fuerza a ser más auténtico, más libre, más generoso, más yo mismo. No es el otro que me obliga a enfrentarme a mis miedos y a asumir mis potencialidades; no es el otro como interpelación personal radical, sino como interrogación racional argumentativa. No se asume la realidad del otro en tanto explotado o marginado por el sistema que a mí, también como sujeto-argumentador, me constituye. Se mira la realidad con un reduccionismo dialógico-idealista que no es el mejor augurio para la consecución de una verdad que me permita ensanchar los propios limites de la realidad que hasta ahora me constituye. La inspiración kantiana ha pasado factura.

Podríamos decir, por tanto, que la tercera dimensión de la libertad ha sido ignorada en las éticas europeas y norteamericanas. De hecho las tres perspectivas éticas con más aceptación en la actualidad integran de manera marginal la lucha contra la injusticia inhumana que está desfigurando nuestra propia humanidad. Son éticas domesticadas por el sistema, en palabras 
de Adela Cortina9. Sin embargo en las éticas que emergen de la periferia del sistema es la dimensión desde la que se comprende la experiencia moral y las otras dimensiones de la libertad.

La libertad-igualdad que Rawls propone ha de ser situado en el horizonte de la realidad concreta. La universalización de los comportamientos como criterio ético no puede ser tomado idealista sino real y concretamente. Los modos de vida no sostenibles ecológica y socialmente son, de suyo, injustos. Los valores que sustentan una sociedad y que han puesto en valor los comunitaristas sólo serán verdaderos cuando hagan justicia a la interdependencia global en la que vivimos. El error ético del comunitarismo es hablar de unas valoraciones éticas de una sociedad concreta y delimitada, cuando esa sociedad cultural y politicamente delimitada se funda en una globalización socio-económica imparable y cada vez más densa y profunda. Si nuestros patrones de justicia no rigen para los trabajadores que manufacturan los componentes del ordenador que compramos en nuestras tiendas no podremos decir que vivimos realmente conforme a la justicia. La virtud de la justicia hoy ha de abrirse a un diálogo cultural global y a la consideración de la globalidad de las sociedades en que vivimos. Pero teniendo en cuenta la desigualdad estructural económica que provoca una intrínseca desigualdad a la hora de poder elaborar y hacer oír argumentos que busquen la justicia desde la situación de los desfavorecidos.

Si el contrato social, el diálogo argumentativo o la tradición cultural no tienen en cuenta la realidad de desigualdad, de injusticia y de inhumanidad en la que se constituyen contrato, diálogo y tradición no pueden abrogarse la honradez con la realidad necesaria para la reflexión filosófica.

\section{IGNACIO ELLACURÍA: HACIA UNA ÉTICA CRÍTICO-REALISTA O DE LA LIBERACIÓN}

La ética de la liberación parte, precisamente, de lo que en la reflexión ética del primer mundo se margina y se pretende olvidar:

9 A. Cortina: Ética mínima. Introducción a la filosofia práctica, Tecnos, Madrid, 1994, p.43ss. 
la interpelación histórica y existencial de las mayorías que viven la pobreza y la injusticia; la interpelación del otro, en tanto pobre y explotado, del otro en tanto negado en sus derechos; la realidad de la injusticia masiva e irracional de colectivos enteros de personas condenadas al hambre, al analfabetismo y a una vida humana cercenada por mecanismos supranacionales de relación políticoeconómica.

La presentación más desarrollada de una ética de la liberación es la de Enrique Dusse ${ }^{10}$. La ética de la liberación tiene como punto de partida la toma de conciencia de la explotación, la marginación y los abusos a los que los colectivos débiles son sometidos. Al partir del reconocimiento, de la resonancia moral del grito de los excluidos integra el momento personal y el momento social de la ética; al partir de la situación de injusticia estructura a la que son sometidos, está abierta a la transformación de la historia y a la búsqueda histórica de la justicia.

Siendo interesante la propuesta de Dussel, voy a centrarme en las intuiciones éticas de Ignacio Ellacuría por la hondura metafísica de su propuesta filosófica. Las profundas raíces zubirianas de su pensamiento quizás hagan posible encontrar una conexión profunda entre la ética y la comprensión estructural y sistemática de la realidad, así como anclarla en la comprensión de la libertad.

La propuesta ética de Xavier Zubiri, siendo rigurosa y creativa, se mantiene dentro de los cánones de la filosofía clásica. Si en metafísica Zubiri fue profundamente innovador, en ética continuó con matices la tradición clásica. Pero su radicalidad metafísica va a permitir a su discípulo Ignacio Ellacuría replantearse de manera radicalmente nueva también la dimensión moral y, por tanto, la reflexión ética y política. Ellacuría no pudo terminar la tarea de formular su ética de la liberación, pero dejó intuiciones suficientes para que recojamos un esbozo de la misma. En este análisis voy a dejarme guiar por un esquema en el que Ignacio Ellacuría esbozó lo que para él sería una ética fundamental. Lo primero que hace es

10 E. Dussel, Ética de la liberación en la edad de la globalización y de la exclusión. Ed. Trotta, Madrid, 1998. 
abordar la cuestión de la pregunta ética fundamental ${ }^{11}$. Es un texto breve pero lleno de intuiciones y caminos de reflexión. Si bien, para su recta comprensión tendremos que acudir a los desarrollos que de algunas intuiciones hace en otros momentos de su reflexión.
a) El realismo como superación de la duda ideologizadora.
b) El camino de la realización de la libertad: la historización de los conceptos.
c) La realización de la historia: teleología e idea regulativa.
d) La problemática exigencialidad de la dimensión moral.
e) Los medios: marxismo o fidelidad a lo real.
f) El poder de los pobres de recrear la realidad: la absolutización de la historia.

\section{a) E1 realismo como superación de la duda ideologizadora}

Para encontrar el fundamento filosófico de la perspectiva ética de Ellacuria hemos de analizar, siquiera brevemente el acto que nos hace personas y que funda nuestra libertad, el acto del conocimiento. El fundamento de la ética de la liberación de Ellacuría no va a estar en la comprensión de la libertad, sino un paso más atrás, en la comprensión del propio acto de conocer. Ya el viejo Aristóteles decía que el silogismo práctico, que alcanzaba la verdad moral, constaba de una premisa mayor que era un desiderátum, un deseo, y un conocimiento que permitía la acción apropiada. El conocimiento, la razón, es premisa de la acción libre. Y en su vocación de fundamentalidad filosófica, Ellacuría va a partir del principio.

Para Zubiri, y para Ellacuría, lo que pone a las personas en el plano estrictamente humano es el acto del conocimiento. Zubiri describe ese acto no como un acto de reflexión, ni de conceptualización, no como una elaboración ulterior a los datos aportados por los sentidos, sino como un acto de aprehensión inmediata, directa y radical de la realidad.

11 I. Ellacuría: "Ética fundamental", en La lucha por la justicia. Selección de textos de Ignacio Ellacuria (1969-1989), [Juan Antonio Senent ed.] Deusto, Bilbao, 2012. 
No pensamos la realidad, las sentimos en aprehensión sentiente. Esta descripción del acto cognoscitivo permite a Zubiri plantear el conocimiento de la verdad no como un problema que necesita solución, sino como realidad que requiere explicación; el conocimiento es una marcha en la senda de la realidad, como un camino en la verdad. No buscamos la verdad sin tenerla; buscamos la verdad más amplia y radical porque ya tenemos una parte de esa verdad, por pequeña que sea, en nuestra impresión de realidad. Toda verdad ulterior, más amplia y general, se fundamentará en la verdad real de la aprehensión de realidad. Zubiri, y Ellacuría con él, se libra de la obsesión por conseguir un inicio prístino e inmarcesible del conocimiento que asegure la veracidad de nuestras posteriores elaboraciones. El primer conocimiento es indudable porque no afirma ni niega, porque no conceptualiza ni estructura, es mera impresión de realidad; después vendrán afirmaciones, generalizaciones, conceptualizaciones y toda una labor intelectual que podrá ir acertando y errar. Pero la impresión de realidad, el volver a la realidad de las cosas, será el criterio de en qué grado nuestras elaboraciones actualizan adecuadamente la realidad, nos dan una imagen fiel de la misma.

Aunque parezca paradójico la obsesión crítica por un conocimiento apodíctico y absoluto ha paralizado las virtualidades criticas de la filosofia. La búsqueda obsesiva de un conocimiento inmaculado, como toda obsesión, paraliza y hace infecunda la reflexión. Es cierto que la preocupación por el rigor intelectivo, la exactitud y la profundidad de las propuestas teóricas es un elemento necesario e imprescindible de toda ciencia, también de la filosófica. Pero esta preocupación no debe convertirse en una cortapisa de la reflexión. Las cuestiones de método han estado ahogando al pensamiento filosófico durante siglos. Mientras los filósofos se perdian en críticas epistemológicas sólo comprensibles para muy iniciados, abandonaban la crítica social más necesaria y evidente. Especialmente ha sido sangrante esta parálisis en el siglo XX: la humanidad desangrándose con guerras y la explotación del Tercer Mundo, y la filosofía neopositivista probando la imposibilidad de la reconstrucción lógica de los enunciados morales...

Ellacuría lo apuntaba: "Las cuestiones de método no son anteriores, contra lo que pudieran pensar Descartes y sus secuaces, al quehacer intelectual, que se ocuparia ya con la resolución de determinados problemas. Supone, incluso temporalmente, una cierta 
posterioridad: después de haber realizado una tarea intelectual productiva, uno se hace cuestión de cómo se ha procedido en ella a modo de justificación teórica, a modo de corrección o a modo de relanzamiento. No sólo las doctrinas y las teorias, sino más aún los métodos, tienen su propio "círculo hermenéutico", y no verso asi, es comenzar acriticamente cualquier intento de critica"12. Para Ellacuría, como para Hegel y Zubiri, la crítica epistemológica ha de ser una constante en nuestro proceso de reflexión, en cada paso del conocimiento. En cada avance del conocer hemos de criticar nuestro conocimiento desde la alteridad de la realidad. Porque la realidad tiene siempre primacía sobre nuestro conocimiento. El papel de la negación que busca una superación de lo actualizado en nuestra forma de conocer y de afrontar la realidad es este.

Ignacio Ellacuría cuando se plantea elaborar una Ética fundamental no va a comenzar desde una búsqueda de un concepto de bien, de deber o de felicidad incuestionable. Es más no comienza su ética preguntándose qué debemos hacer. Su inicio reflexión parte de la realidad que radicalmente se percibe como inhumana, injusta y mala. No toma como punto de partida de la ética la problematicidad del concepto de bien o de deber. No tiene como arranque los sentimientos subjetivos de culpabilidad que acompañan determinados comportamientos. Toma como punto de partida la radical y más evidente situación de la realidad que estaba viviendo. $\mathrm{Y}$ es que la realidad que irrefragablemente impresiona, golpea, a quien está situado entre los pobres de la humanidad es la situación inhumana de sufrimiento y explotación en la que viven tantos.

"La pregunta por el hacer humano es una pregunta por un hacer humano situado, y la situación fundamental histórica en la que el hombre se encuentra es una situación que se siente y se pre-juzga como mala. En este momentos no tenemos todavia un criterio racional explicito para juzgar como buena o mala moralmente una situación, pero lo que es evidente es que no partimos de una situación neutra, sino de una situación fundamentalmente deshumanizadora del hombre. La presencia del mal en el mundo es tan masiva y de tal implicación con la vida personal de los hombres, que, abstracción hecha de la culpabilidad, no se puede negar la realidad objetiva del mal y la presencia de la voluntad histórica del hombre en la realización de ese mal" 13.

12 I. Ellacuría, "Hacia una fundamentación del método teológico latinoamericano" en Revista de Estudios Centroamericanos 322/323 Agosto-Septiembre 1975, 409.

13 I. Ellacuria: "Ética fundamental", p.42. 
Este el contexto radical de la pregunta fundamental de la ética y es el contexto radical en el que hoy nos tenemos que constituir como personas. "La pregunta fundamental de la ética es una pregunta por el hacer humano (...) Lo que se pregunta es por la tarea de ser hombre, por el oficio de ser hombre: qué se requiere para ser humano y que es lo que hay que hacer para ser humano"14. Lo que seamos como personas estará definido, fundamentalmente, en la respuesta que demos a la realidad en la que estamos situados. Puede parecer obvio, pero cuántos autores se enredan en sentimientos, en leyes y en deberes sin preguntarse por la concreción de la repercusión de nuestro comportamiento en la situación en la que nos encontramos.

No tenemos criterio racional explícito, pero se "pre-sabe", se experimenta con evidencia la deshumanización en la que viven muchas personas. La pregunta fundamental de la ética es una pregunta que tiene como verdad real en la que se sitúa la inhumanidad del hambre, de la guerra, de la muerte por enfermedades evitables, de las mujeres explotadas y mutiladas, de los jóvenes con su futuro vital truncado por la falta de empleo. Ignorar esa instauración de realidad en nuestro preguntar ético es insostenible racionalmente y culpable filosófica y humanamente. Y, sin embargo como decía, las corrientes morales occidentales ignoran en su pregunta fundamental de la ética esta situación.

Esta pregunta fundamental de la ética es tan radical que no sólo estará presente en los comportamientos de los que somos responsables, sino también en las situaciones que vivimos y que nos vienen dadas antes de que entre en juego nuestra libre decisión. La situacionalidad de nuestra vida ha de ser tenida en cuenta "tanto por lo que su hacer tiene de efectivo sobre lo que no es él mismo, como lo que su hacer tiene de condicionado por lo que no es él mismo"15. No somos sólo lo que hacemos nosotros mismos desde nuestra libertad; también somos lo que nos hizo personas en la ambigüedad de toda la humanidad. Tanto somos, aunque no de la misma manera, lo que se nos entregó, sin contar con nuestra voluntad, como lo que acogimos consciente y libremente

14 Idem.

15 Idem. 
con nuestras decisiones. Ambas cosas somos las personas, con ambas cosas ha de lidiar el oficio de ser hombres. Previa a todo contrato social, a toda valoración psicológica, a toda conciencia de deber y a todo diálogo argumentativo está la realidad en la que nos constituimos.

\section{b) El camino de la realización de la libertad: la historización de los conceptos}

Esta dinámica intelectiva de asumir la situación en que nos encontramos no es sólo una decisión epistémica consciente, sino que manifiesta una estructura metafísica del acto de conocer. Cada impresión de realidad que tenemos trae intrínsecamente, de manera congénere dice Zubiri, la instauración en la realidad de la realidad que nos impresiona. Cada impresión de realidad es impresión de instauración en la realidad propia, del ser que conoce, y de la realidad conocida. En el más sencillo y simple acto de nuestra vida las realidades se nos ofrecen en alteridad a nuestra propia intelección, en dinamismo constitutivo, y en instauración en el mundo. " $L a$ instauración en la realidad está radicalmente dada en impresión de realidad. De aqui resulta que realidad en cuanto realidad no es un mero concepto, sino que es fisica instauración en la realidad"16. O en palabras de Ellacuría: "La unidad entre inteligencia y realidad no es una relación sino una respectividad: es el estar aprehensivameante en la realidad. Estamos en la realidad sentientemente en un estar meramente actualizando lo aprehendido en que estamos, de modo que forzosamente $y$ ab initio estamos instalados en la realidad, no sólo en cada cosa real que aprehendemos sino eo ipso en la realidad que se hace presente en la impresión de realidad"17.

Esta dimensión del acto cognoscitivo de la instauración en la realidad no sólo servirá para asumir un punto de partida una perspectiva de crítica realista e histórica, sino que estará presente

\footnotetext{
Xavier Zubiri , Inteligencia sentiente, Ed. Alianza, Madrid 1984, 214.

17 I. Ellacuría, "La superación del reduccionismo idealista" en Palacios Y Jarauta, (Editores) Razón, ética y política. El conflictos de las sociedades modernas, Editorial Antrhopos, Barcelona, 1989, p.188.
} 
en todo el camino de conocimiento moral de la realidad. Esto es lo que asume y consigue el método de la historización de los conceptos. Yo no conozco la verdad y el alcance de los conceptos que me hago de la realidad hasta que no veo cómo se instauran en la realidad, hasta que no se corroboran los dinamismos que fundan y posibilitan. El derecho a la propiedad, el derecho a la libertad individual, etc., han de mostrar su verdad radical en la instauración en la realidad. La verdad no es veracidad de conceptualización, sino verdad de realidad, verdad de instauración en la realidad. Por eso, la conceptualización liberalista de los derechos humanos no es que sea falsa; en el momento de promulgarse manifestaron una verdad fundamental y la siguen manifestando; pero si no se asumen dinámicamente se puede falsear su contenido; si se aplican abstractamente, sin ir descubriendo los dinamismos de realización o desrrealización que implementan, pueden acabar significando lo contrario de lo que promulgan. Si esos derechos humanos se aplican sólo a varones blancos y poseedores de unos determinados bienes como se hizo cuando surgieron, se cercenará su dinamismo de verdad. Al oponerse al régimen aristocrático tenían una gran verdad en su seno, pero necesitan ser historizados.

Los conceptos ético-políticos no pueden heredarse del pasado en una recepción pasiva. Ya la metafísica zubiriana de la historia, de la que Ellacuria es profundamente deudor, aclaraba que toda tradición heredada ha de ser continuada creativamente para ser fiel a sí misma. Hacer lo mismo en circunstancias históricas distintas es hacer, efectivamente, otra cosa distinta. Si la "tradición" pierde la "d" de "dinamismo", se convierte en flagrante "traición" e infidelidad. La historización es el "remedio metodológico a los desvios fundamentales de la ideologización"18; no es sólo un método de hermenéutica desde el pasado, es una metodologia de análisis del presente y hacia el futuro. El principal dinamismo desenmascarador de la historización se encuentra en el análisis de los hechos presentes.

18 I. Ellacuria, "Ideología e inteligencia”, en La lucha por la justicia. Selección de textos de Ignacio Ellacuría (1969-1989), [Juan Antonio Senent ed.] Deusto, Bilbao, 2012, p.125. 
"Su principio fundamental es que la verificación histórica muestra si es verdad y en qué sentido lo es cualquier formulación abstracta, por ejemplo, si se dice que la propiedad privada de los medios de producción es principio necesario para la libertad o para la justicia y se verifica históricamente que lo que produce de hecho esa propiedad privada es lo contrario, concluiremos que ese principio carece de verdad realmente histórica y que es un subterfugio ideológico para hacer pasar como junta una realidad injusta; si, al contrario, se verifica que produce lo que afirma, queda mostrado por la historización que en determinadas circunstancias ese principio no es ideológico"19.

Ellacuría afirma que con este método "se da primacía a la realización, que es el elemento descubridor, sobre el de la racionalización, que es el elemento encubridor"20. Es la primacia que siempre ha de tener la realidad sobre la racionalización de la misma. Es la realidad la que ha de ser actualizada por la intelección; es la realización auténtica la que tiene que ser historizada por nuestros esfuerzos racionales.

No se trata de que los conceptos sean equívocos, sino que para acceder a la verdad real hemos de tener en cuenta esta necesaria labor de historización que ha de hacer la filosofia. Historizar un concepto es decir lo que significa y oculta aquí y ahora. No es lo mismo la propiedad de la tierra en el feudalismo que hoy día, no es igual la propiedad de una fábrica a la de un programa de ordenador, no es lo mismo la libertad de prensa escrita en el XIX que hoy día en que un periódico, una radio o una emisora de televisión sólo pueden ser sostenidos por un gran capital. Historizar un concepto, por ejemplo el derecho a la propiedad, es primero definir estructuralmente a qué se refiere, en relación con las distintas concreciones históricas y sociales en las que se ha dado. Segundo descubrir qué repercusiones tiene su aplicación en la realidad, cómo funciona en esta sociedad en este momento.

La historización de los conceptos, valores o ideales éticos ha de hacerse desde la situación y la perspectiva de los que el sistema económico explota o expulsa, y desde la perspectiva de los que el sistema ideológico ignora.

19 Idem.

20 Idem. 


\section{c) La realización de la historia: teleologia e idea regulativa}

La segunda de las dimensiones de la libertad habiamos señalado que era la de vivir conforme al bien, la capacidad de ir construyendo una vida buena de la que la persona se sintiera satisfecho y en la que fuera feliz. Ellacuría amplía el horizonte de esta dimensión de la persona a la realidad de la historia. La pregunta por el bien moral no puede restringirse a un ámbito individualista, el bien para mí, sino que ha de abrirse necesariamente a la realización de la historia: "¿Qué y cómo debemos hacer para que la historia llegue a humanizar al hombre y el hombre llegue a humanizar y plenificar la historia"'1. Esta segunda pregunta por el quehacer humano necesita una concreción del concepto de historia y del concepto de plenitud. La ética de la liberación apunta de manera clara que los hombres vivimos nuestra humanidad en el seno de una sociedad y en el curso de una historia, y, por tanto, la plenitud humana no puede perfilarse sin la plenitud de la historia; la pregunta por la verdad de nuestra humanidad no puede desentenderse de lo social y lo histórico.

La ética griega, y otras éticas antiguas también, tenía como horizonte de reflexión la figura del sabio. La ética de la liberación tendrá como horizonte la vida del pueblo. En palabras de Ignacio Ellacuria: "La humanización del hombre por la historia y la humanización y plenificación de la historia por el hombre marcan la dirección, la finalidad -el para qué- del hacer moral"22. Esta finalidad de la historia, por el carácter radicalmente dinámico del conocimiento en Ellacuría, no pueden definirse de una vez por todas, de tal manera que siendo un fin teleológico al que tender, es, a la vez, una idea regulativa de la acción y de la reflexión ética, filosófica y política. "Qué es la realidad últimamente solo lo sabemos en su hacerse historia; lo que se revela es la realidad misma que se va realizando, y la realidad asi revelada se convierte en la verdad de la historia. La historia es así revelación y principio de revelación”23.

La alternativa entre finalismo y deontología, entre ética material y ética formal se diluye en la ética de la liberación de Ignacio Ellacuría

\footnotetext{
I. Ellacuria:"Ética fundamental", p.43.

Ibid, p.45.

23 Ibid, p.44.
} 
porque si bien se constata que el actuar humano tiene un fin y que ese fin es el bien, la plenitud de las personas en la historia, ese fin no está dado de una vez por todas como un concepto cerrado, sino que es una idea que regula nuestra reflexión y nuestra propia acción transformadora de la historia. La universalidad o la dignidad humana como concepto regulativo en Kant y la perfección del hombre sabio y magnánimo en Aristóteles como concepto definido encuentran una sintesis en esta finalidad abierta de la plenificación de la persona en la historia. La plenitud del hombre a través de la historia ha de irse definiendo en el mismo proceso de la historia, desde las condiciones materiales de la misma. La des-logificación de la inteligencia que realizó Zubiri permite a Ellacuria proponer un horizonte moral material sin caer en un concepto ya predefinido, ya pre-sabido del mismo.

La "formalidad" de esta teleología marca una dirección fundamental que ha de regir nuestra praxis, nuestras búsquedas y proyectos. Esa idea regulativa la encuentra en el concepto de Zubiri de la historia como proceso trascendental de capacitación y de personalización ${ }^{24}$. Y es que para Ellacuría, "la historia es asi el acto mismo de la revelación de la realidad"25. Por tanto la materialidad de esa idea regulativa, la concreción de esa finalidad de la historia no la podemos definir en un momento de la historia, sino en el decurso de la misma. En Ellacuría ni la formalidad anula la teleología, ni la teleología anula la formalidad:

"Todo lo dicho nos lleva a la afirmación de que la historia tiene sentido (...) Y esto no sólo como conexión e interpretación de acontecimientos sino también como explicación metafisica de la realidad histórica en cuanto tal. Desde este sentido fundamental, que ha supuesto la conceptuación de la estructura formal de la historia y del proceso histórico como totalidad de lo real, puede uno preguntarse por los posibles sentidos de la historia; pregunta que está enmarcada en el horizonte de este sentido fundamental, pero que deberá ser concretada desde el análisis de los hechos históricos y desde la busca de leyes históricas”.

24 Ibid, p.43.

25 I. Ellacuria, "El sentido de la historia", en J.A. Senent-J.J. Castellón: "Persona y comunidad. Dos textos inéditos de Ignacio Ellacuria", Isidorianum X (2001), $n^{\circ} 19$, p.90.

26 Ibid, p.88. 
La constitución de la utopía ha de ser, asimismo, histórica; esa utopia siempre ha de buscar que todos los hombres y mujeres tengan una vida más plena.

\section{d) La problemática exigencialidad de la dimensión moral}

Una reflexión por la pregunta fundamental de la ética no puede pasar por alto un tema espinoso, dificil, ambiguo, pero radical: la experiencia de la obligación moral. Este problema ocupó a Ellacuría en varias ocasiones, sin que diera una respuesta que a él mismo lo satisficiera por completo. Es como si dejara en un compás de espera la pregunta por la exigencialidad de la acción moral.

¿Por qué nos sentimos obligados a actuar de una manera o de otra? ¿Qué o Quién nos exige desde dentro de nosotros mismos a tomar partido por el bien y la justicia? ¿Qué mecanismos psicológicos o sociológicos están a la base de la exigencialidad del bien, de la integridad o de la justicia? Estas preguntas quedan siempre aplazadas en el discurso filosófico de nuestro autor. No dice nunca que no puedan responderse y que haya que acudir necesariamente a la experiencia religiosa para responderlas. Pero las elude abriendo el abanico de posibles respuestas. Así lo hace en el esquema de Ética fundamental. "El carácter exigencial es, por lo pronto, un hecho, por más que esta exigencia pueda explicarse de muy distintas formas (moral kantiana, moral tomista, etc.) y se le puedan atribuir mecanismos muy diferentes (Marx, Freud, Marcuse, etc.)"27.

Quizás sea en el diálogo con la filosofia existencialista, en el análisis existencial de la persona, donde encuentra una mayor luz en este dificil tema filosófico. "La misma estructura de la persona y de la historia presenta la existencia personal y la existencia histórica en términos de existencia, de un estar saliendo de lo que ya se es en busca de otro modo de ser, que a su vez debe superarse activamente"28. $\mathrm{Y}$, efectivamente, es en unos artículos sobre el último Sartre donde avanza en la intelección del fundamento del hecho de la obligación.

27 I. Ellacuria:"Ética fundamental", p.44.

28 Ibid, p.44. 
La relación interpersonal es el horizonte de este diálogo de Ellacuría consigo mismo a propósito de la obra del autor existencialista. Podemos ser para los otros de múltiples maneras, pero siempre tendremos que definir nuestra vida desde nuestro ser para los demás. Pues solamente siendo para los otros podremos ser nosotros mismos.

"Se está "ya" con el otro y esto condiciona la propia conciencia. Pero no necesariamente en el sentido de que pensamos lo que piensan los otros o juzgamos lo que los otros juzgan; no en el sentido de que se nos impone desde fuera la obligación y el contenido de la obligación. Todo esto puede ocurrir, pero no es lo que debe ocurrir para completar nuestra conciencia total. Esta totalización de la conciencia es la que reclama que el otro está presente a la hora de constituirme como yo mismo. No se trata de que lo haga presente, sino de que presencialice al otro ya presente en mi conciencia moral, que tome conciencia de su actualización ya real en mí mismo"29.

El carácter de obligatoriedad, de exigencia, surge de la apertura humana que nos fuerza a superarnos activamente tanto en nuestra dimensión personal como histórica, pero surge siempre en relación con los otros. Y esto tiene rango de realidad dada, "de hecho, ni objetiva ni subjetivamente se da la exigencialidad, sino con los otros y de cara a los otros, sin que esto implique el que los otros intervengan en uno como su propio Súper-Yo"so. "El hombre es ser-para-los-otros y no meramente ser-con-los-otros" 1 . Mi realización personal ha de continuar el dinamismo que me hizo persona. Ese dinamismo está configurado por la entrega que muchos me hicieron de su vida cuando todo lo necesitaba, en mi primera niñez. Nos hizo personas la entrega incondicional, sacrificada y gratuita de quien asumió nuestra crianza. Nuestra realización personal, para no entrar en contradicción con lo que somos, ha de buscar cómo entregarnos incondicional y gratuitamente a los demás, en cómo ser para los otros. Si en este diálogo con Sartre es la experiencia personal la que fuerza la salida de lo que uno es hasta ahora, en el esquema de Ética fundamental se nos apunta que la exigencialidad general "cobra un carácter

\footnotetext{
29 I. Ellacuría: "El testamento de Sartre", en Revista de Estudios Centroamericanos, 387-388 (1981), p.48.

30 "Ética fundamental", p.45.

31 I. Ellacuria "El testamento de Sartre", p.48.
} 
especial en la experiencia del mal en el mundo, sobre todo cuando se manifiesta como opresión e injusticia, junto con la experiencia de una necesidad de salvación de ese mal" ${ }^{32}$.

La ética ellacuriana no tiene una asunción directa de la interpelación del otro como camino de justicia y libertad, en el sentido de Levinás. Quizás Ignacio Ellacuría pudiera pensar que este concepto de la interpelación del otro tiene demasiadas resonancias sentimentales y subjetivas, o quizás que hubiera que asumirlas desde otra dimensión de la inteligencia, desde la dimensión de religación, en la vertiente propiamente religiosa. Esta interpelación del otro estará muy presente en él, pero desde la dimensión religiosa, como suele decir J. Sobrino, la llamada a bajar a los crucificados de la cruz.

\section{e) Los medios: marxismo o fidelidad a lo real}

Otro de los pasos que se tiene que ir dando en el camino de realización de la libertad, personal y social, es el paso de los medios. Quien no tiene claros los medios no podrá conseguir el fin; quien no realiza los medios no realizará nunca el fin; o como dice Ellacuría, recogiendo un dicho del pueblo: "quien quiere el fin quiere los medios". No hay verdadera búsqueda de la realización de la historia si nuestra inquietud se queda en una generalidad que no concreta los pasos por los que la realidad ha de ir cambiando. Lo mismo que la verdad ha de ser justa, tener justeza y estar ajustada, la verdad moral y la verdad politica. "Afirmar que se quiere la libertad, el amor, etc., sin poner las condiciones históricas reales que hacen posible la libertad el amor, etc., es una mistificación, un engaño para que el hombre no sea realmente lo que decimos que debe ser"33.

Ellacuría entiende que una reflexión ética abstracta, sea material o formal, es una ética falseadora. No sólo hemos de preguntarnos qué debemos hacer, sino cómo debemos hacer lo que debemos. La respuesta a esa pregunta por el cómo sólo podrá encontrarse acudiendo, de nuevo a la realidad: "El método para responder a

32 "Ética fundamental", p.45.

33 Ibid, p.44. 
esta pregunta tiene que ser una vuelta a la realidad para descubrir racionalmente qué es o que se debe hacer y cómo se debe hacer. Esta prioridad de la realidad sobre toda forma de construcción subjetiva es un principio fundamental para resolver racionalmente cualquier problema" 34 . Por esto, no puede defenderse de ningún modo que las propuestas ético-políticas de Ellacuría tengan raíz marxista.

El contexto dialogal de los años 70 y 80 en Europa y América Latina para muchos sectores intelectuales era el marxismo. La situación política de El Salvador y de muchos otros países de América también lo era. Por eso en muchas ocasiones el discurso de Ignacio Ellacuría asume expresiones y argumentos de segundo orden del marxismo. Pero su filosofia encuentra fundamento radical en la metafísica zubiriana. El marxismo, por su entronque con la metafísica sustancialista hegeliana, ya sabe la estructura del dinamismo de la realidad, como Hegel sabía la estructura del dinamismo de la razón. Ellacuría es profundamente realista y siempre será la realidad la que tenga preeminencia sobre la idea.

"No es la filosofia obra del filósofo, sino el filósofo obra de la filosofía. Es que el filosofar mismo se inicia por una urgencia interior, que impele y constituye al filósofo; y prosigue por el dinamismo de la realidad misma que se actualiza en la mente del filósofo. Esta realidad que obliga al filósofo a perseguirla antes y más allá de todo concepto, es la que tiene la primacía sobre el filosofar ${ }^{335}$.

Por tanto ningún esquema de la razón, sea dialéctico o no, ninguna idea preconcebida del dinamismo social, sea marxista o no, va a tomar carta de naturaleza en la filosofia ellacuriana si no es la realidad la que lo avala en cada caso y situación. Podrá ser que en determinadas situaciones la sociología de corte marxista recoja los datos de la realidad y sus procesos estructurales, pero en absoluto puede haber una pre-comprensión que se imponga o que nos disculpe del análisis de la realidad. En la reflexión que vamos siguiendo de Ellacuría de "Ética fundamental" se dice de forma categórica: "El método para responder a esta pregunta tiene que ser

\footnotetext{
Idem.

35 Ignacio Ellacuria, "La idea de filosofia en Zubiri"; en Homenaje a Xavier Zubiri, Madrid 1970; Tomo I, p.463.
} 
una vuelta a la realidad para en ella descubrir racionalmente qué es lo que se debe hacer y cómo se debe hacer. Esta prioridad de la realidad sobre toda forma de construcción subjetiva es un principio fundamental para resolver racionalmente cualquier problema"36. El análisis marxista es situado en esta reflexión como elemento a tener en cuenta junto con el freudiano y el de la filosofia del lenguaje. Reflexiones parciales que pueden manifestar una verdad parcial.

\section{f) El poder de los pobres de recrear la realidad}

No asumiriamos la totalidad del planteamiento ético ellacuriano sin atender a al poder que tienen los pobres para recrear la realidad social y la realidad personal de quien a ellos se acerca.

La realidad tiene poder, decía Zubiri; y ese poder enigmático de la realidad es la vía de acceso que propone el autor vasco para descubrir la dimensión religiosa. Vivimos religados a la realidad y esa religación es la experiencia radical que está a la base de las diversas experiencias religiosas. Para Ignacio Ellacuría la tarea de la lucha por la liberación es una llamada a bajar a los pueblos crucificados de la cruz. Y esa tarea concreta tiene un poder enigmático tal que puede transformar la realidad de quien la asume; "supera la dicotomía del acto interior y acto exterior, acto intencional y obra realizada, acto individual y acto social. En definitiva, abarca el existir humano en cuanto unidad y totalidad"37, y que plenifica la historia. La tarea de la ética es reflexionar sobre el quehacer humano de plenificar la realidad y de realizarse plenamente la persona misma: “¿Qué y cómo debemos hacer para que la historia llegue a humanizar al hombre y el hombre llegue a humanizar y plenificar la historia?"38. Y la plenitud de lo humano, para un filósofo creyente, siempre estará en íntima relación con la experiencia de Dios. Hasta la verdad última de lo que somos y lo que a realidad se nos revelará históricamente: "qué es la realidad últimamente sólo lo sabemos en su hacerse historia"39. La historia es cauce de la revelación misma.

\footnotetext{
Ignacio Ellacuria, "Ética fundamental", o.c., p. 46.

Ibid, p. 42.

Ibid, p.43.

39 Idem.
} 
Como podemos ver, revelación, plenitud, ultimidad son términos y conceptos cercanos a lo religioso y es que para Ellacuría voluntad de realidad, voluntad de acoger la realidad en su verdadera dimensión, y voluntad de fundamentalidad, voluntad de abrirnos al fundamento último, trascendente, de la realidad, están en íntima relación. Frases como: "la salvación vendrá de los pobres" nos muestran hasta qué punto el dinamismo de liberación de los pobres es un proceso de recreación de toda la realidad, una recreación que es dinamismo trascendental, de crecimiento real de realidad.

\section{A MODO DE CONCLUSIÓN}

La ética de Ellacuría, al posibilitar una reflexión sobre los valores de nuestra cultura desde la perspectiva de una praxis histórica que humanice realmente la vida de las personas y los pueblos tiene importantes luces:

Nos propone un universalismo realista y crítico, no meramente intencional. El universalismo moral ha de pasar por la critica de la realidad histórica concreta. Muchas reflexiones éticas, hechas desde un aburguesamiento nihilista postmoderno, se olvidan de las repercusiones reales de sus propuestas y de las raíces socioeconómicas de su propia constitución.

La reflexión ellacuriana parece no asume con la radicalidad que lo hace, por ejemplo, la ética de la liberación de Dussel la realidad del multiculturalismo o los valores de las culturas indígenas. Pero su intuición de que nuestra historia es ya indefectiblemente una historia en la que todos los pueblos del mundo están realmente vinculados, que nuestra reflexión ética ha de responder a esa realidad, y su descripción de la realidad metafisica del pueblo, hace que tenga importantes virtualidades en el diálogo multicultural.

Una de las intuiciones más fructíferas de la constitución de su ética crítica es asumir la vida de los últimos como verdadera perspectiva de universalidad y de humanización. Sin esta forma de entender la universalidad toda reflexión ética cae en el peligro de convertirse en una ética reformista de los valores del sistema cultural en el que han surgido, sin atender a la necesidad de una 
transformación radical de un mundo que condena a tantas personas a condiciones inhumanas de vida por explotación económica, ya sea expresada en explotación laboral, en corrupción de las élites de países dependientes, ya sea, incluso, en guerras civiles con el catalizador de evidentes intereses económicos.

Otra importante virtualidad del pensamiento ellacuriano es cómo disuelve la alternativa entre la ética material, abierta a un concepto de bien y de plenitud humana, y la ética formal que posibilita una definición autónoma de la propia vida para cada persona y cada pueblo. Para Ellacuría el bien común, la justicia, la plenitud de la historia son concepto que no están dados de una vez por todas, sino que los tenemos que ir descubriendo y construyendo en la historia. Descubrir y construir parecen dos verbos contradictorios. Una cosa es descubrir lo que ya estaba dado; otra que mi acción o mi pensamiento pongan lo que no estaba. Como la historia es una realidad que no está ya hecha, aunque tiene dinamismos reales de humanización que respetar, nuestro quehacer para plenificarla ha de estar atento a esos dinamismos reales, que no nos podemos inventar ni ignorar, y, a la vez, ha de tener la osadia de buscar caminos nuevos que los actualicen de manera adecuada. No nos inventamos nuestra realidad, y cuando lo hemos querido hacer hemos explotado y oprimido a los más débiles y a nosotros mismos. No podemos dejar de reinventar nuestro futuro, y cuando nos hemos negado a hacerlo hemos caído en una traición a los valores que pretendiamos potenciar.

La última virtualidad de la ética de Ellacuría que señalo es cómo asume la trascendentalidad del quehacer humano, que tiene poder para cambiar su propia realidad y la realidad histórica. Y, a la vez, se abre al poder de la realidad de los otros, de los pobres, para acoger la realidad poderosa con que pueden dar plenitud a la realidad personal e histórica. Esta trascendentalidad de la ética ellacuriana puede asumirse como apertura al fundamento trascendente de la realidad y abrirse a la experiencia religiosa; o comprenderla como el misterio de una realidad que nos desborda y ante cuya grandeza no podemos sino sobrecogernos. 